The authors reported no conflicts of interest.

The Journal policy requires editors and reviewers to disclose conflicts of interest and to decline handling or reviewing manuscripts for which they may have a conflict of interest. The editors and reviewers of this article have no conflicts of interest.

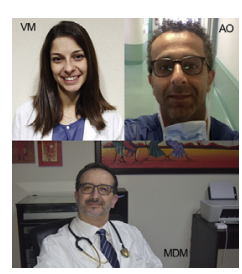

REPLY: SMALL AORTIC ANNULUS: CAN WE DISPEL ALL THE HAMLETIC DOUBTS?

\section{Reply to the Editor:}

The great merit of Derrick Tam and the Toronto University Group ${ }^{1}$ was to turn the spotlight on aortic root enlargement (ARE) during aortic valve replacement, as demonstrated by the letter of De Martino and colleagues. ${ }^{2}$ The latter rightly pointed out the matter of surgical technique used for ARE. In 2014, the same group published the very long-term results of a small cohort of 53 patients undergoing aortic valve replacement (AVR), where enlargement of the aortic annulus was achieved using the Manouguian technique, ${ }^{3,4}$ extending so the aortotomy to separate the commissure between the left and noncoronary sinuses into the anterior mitral leaflet and closing the resulting defect with an adequately tailored patch of bovine pericardium; no case of severe patientprosthesis mismatch (PPM) and no late aortic root aneurysm were recorded. However, the safety and efficacy of ARE have been already demonstrated in a very large single-center experience ${ }^{5}$ where 1854 patients undergoing ARE were compared with 5185 patients receiving lone AVR. In the last decades, we have witnessed an overwhelming number of AVRs performed each year, with a significant shift from mechanical toward bioprosthesis implantation due to the reluctance of even younger patients to take oral anticoagulants. ${ }^{6}$ Subgroup analysis in mismatch studies suggest that PPM is most detrimental in younger patients $^{7}$ and in patients with depressed left ventricular function, ${ }^{8}$ both of whom are becoming more and more prevalent in cardiac surgery. Therefore, if the evidence is by now clearly in favor of ARE to avoid PPM, dispelling one of the many Hamletic doubts in cardiac surgery, the advent of sutureless bioprosthesis may raise a new question: is it better to use a rapid-deployment bioprosthesis, easily to manage even for younger surgeons, or to perform a more technically demanding procedure that, even as safe as AVR, needs most experience? A small-cohort study addressed this topic, ${ }^{9}$ with the authors concluding that "sutureless valve implantation is an alternative to conventional ARE to treat a small aortic annulus and avoid PPM, especially in geriatric patients who benefit from the quick implantation process." However, further large- cohort studies deserve to solve definitively this arising doubt.

Aziz, Omar, $M D^{a}$

Valentina Mancini, $M D^{a}$

Michele Di Mauro, MD, PhD, MSc ${ }^{b, c}$

${ }^{a}$ Dipartimento di Scienze Cliniche e Bioimmagini

Università degli Studi G. d'Annunzio

Chieti-Pescara, Italy

${ }^{b}$ Cardio-Thoracic Surgery Department

Heart \& Vascular Centre

Maastricht University Medical Centre

Maastricht, The Netherlands

${ }^{c}$ Department of Cardiology

"Pierangeli" Hospital

Pescara, Italy

\section{References}

1. Tam DY, Dharma C, Rocha RV, Ouzounian M, Wijeysundera HC, Austin PC, et al. Early and late outcomes of aortic root enlargement: a multicenter propensity score-matched cohort analysis. J Thorac Cardiovasc Surg. 2020;160:908-19.

2. De Martino A, Milano A, Bortolotti U. Facing the small aortic root in aortic valve replacement: enlarge or not enlarge? J Thorac Cardiovasc Surg. 2021;161:e157-8.

3. Celiento M, Saccocci M, De Martino A, Nardi C, Faggioni L, Milano AD, et al. Stability of aortic annulus enlargement during aortic valve replacement using a bovine pericardial patch: an 18-year clinical, echocardiographic, and angiocomputed tomographic follow-up. J Thorac Cardiovasc Surg. 2014;147:977-83.

4. Manouguian S, Seybold-Epting W. Patch enlargement of the aortic valve ring by extending the aortic incision into the anterior mitral leaflet. New operative technique. J Thorac Cardiovasc Surg. 1979;78:402-12.

5. Rocha RV, Manlhiot C, Feindel CM, Yau TM, Mueller B, David TE, et al. Surgical enlargement of the aortic root does not increase the operative risk of aortic valve replacement. Circulation. 2018;137:1585-94.

6. Head SJ, Çelik M, Kappetein AP. Mechanical versus bioprosthetic aortic valve replacement. Eur Heart J. 2017;38:2183-91.

7. Moon MR, Pasque MK, Munfakh NA, Melby SJ, Lawton JS, Moazami N, et al. Prosthesis patient mismatch after aortic valve replacement: impact of age and body size on late survival. Ann Thorac Surg. 2006;81:481-9.

8. Kulik A, Burwash IG, Kapila V, Mesana TG, Ruel M. Long term outcomes after valve replacement for low-gradient aortic stenosis: impact of prosthesis-patient mismatch. Circulation. 2006;114(suppl 1):I553-8.

9. Beckmann E, Martens A, Alhadi F, Hoeffler K, Umminger J, Kaufeld T, et al. Aortic valve replacement with sutureless prosthesis: better than root enlargement to avoid patient-prosthesis mismatch? Interact Cardiovasc Thorac Surg. 2016;22:744-9.

https://doi.org/10.1016/j.jtcvs.2020.10.141

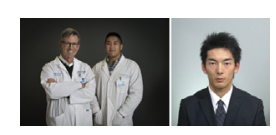

REPLY FROM THE AUTHOR: AORTIC ROOT

\section{ENLARGEMENT- MORE IMPORTANT THAN EVER?}

Reply to the Editor:

We thank Martino and associates for their letter and interest in our study comparing early and late outcomes in those who underwent isolated aortic valve replacement (AVR) versus those who underwent AVR with concomitant aortic root enlargement (ARE) in 11 
The authors reported no conflicts of interest.

The Journal policy requires editors and reviewers to disclose conflicts of interest and to decline handling or reviewing manuscripts for which they may have a conflict of interest. The editors and reviewers of this article have no conflicts of interest.

Ontario cardiac surgical centers from 2008 to $2017 .^{1,2}$ There are several strategies to treat the small aortic root, including the use of stentless aortic valves, full root replacements, and more recently, sutureless valves as well as transcatheter valves. ARE with a patch is an important adjunct in the armamentarium to treat the small aortic root, given its ease and reproducibility. As Martino and colleagues have astutely pointed out, we were unable to tease out which specific ARE technique was used in the 11 Ontario cardiac surgical centers. ${ }^{2}$ Studies suggest that the 3 common techniques (Manougian, Nunez, and Nicks) yield similar results and allow for the implantation of at least one size. ${ }^{3}$ Nonetheless, the comment highlights one of the trade-offs of using an administrative dataset that allows for a large sample size from multiple institutions at the cost of data granularity, which is often less detailed than those collected in single-center registries. ${ }^{4}$ Nonetheless, there are investigators in Toronto, Canada, that are actively working toward transferring echocardiographic data for linkage at ICES (formerly known as the Institute for Evaluative Clinical Sciences), the very same databases that were used in our analysis. We hope that this linkage can help enrich future studies.

While the use of biological valves was considered high in our study (approximately $80 \%$ ), this is consistent with a recent study that evaluated trends in the Society of Thoracic Surgeons Adult Cardiac Surgical Database, which have shown a rapid decline in the use of mechanical valves and a rapid increase in biological valves, particularly in younger patients (those $<60$ years). ${ }^{5}$ This segues into Martino and colleagues' final point in that ARE is an important surgical adjunct, particularly in young patients who undergo an AVR with a biological prosthesis who are at high risk for valve failure during their lifetime. ${ }^{2}$ Many of these patients may be relying on transcatheter valve-in-valve as a low-risk reintervention option should biological prosthesis failure occur. ${ }^{6}$ While recent observational studies have suggested that valve-in-valve may be a safe strategy in the short term, Dvir and colleagues have shown that the placement of a transcatheter valve into a $\leq 21$-sized previous aortic biological prosthesis is associated with a doubling in 1 -year mortality compared with valves $>21$ in size. ${ }^{7,8}$ While balloon valve-fracturing techniques have been developed to circumvent some of issues of a small aortic prosthesis, an initial preventative strategy by using ARE to ensure that an adequately sized biological prosthesis is implanted at the index surgery may help facilitate future valve-in-valve. ${ }^{9}$ As such, ARE as an adjunct may become more important than ever in the evolving treatment of severe aortic stenosis in the era of transcatheter valves replacement.

Derrick Y. Tam, $M D, P h D$ Junichi Shimamura, $M D, P h D$ Stephen E. Fremes, MD, MSc Division of Cardiac Surgery Schulich Heart Centre Department of Surgery Sunnybrook Health Sciences Centre University of Toronto Toronto, Ontario, Canada

\section{References}

1. Tam DY, Dharma C, Rocha RV, Ouzounian M, Wijeysundera HC, Austin PC, et al Early and late outcomes following aortic root enlargement: a multicenter propensity score-matched cohort analysis. J Thorac Cardiovasc Surg. 2019;160: 908-19.e15.

2. De Martino A, Milano AD, Bortolotti U. Facing the small aortic root in aortic valve replacement: enlarge or not enlarge? J Thorac Cardiovasc Surg. 2021; 161:e157-8.

3. Yu W, Tam DY, Rocha RV, Makhdoum A, Ouzounian M, Fremes SE. Aortic root enlargement is safe and reduces the incidence of patient-prosthesis mismatch: a meta-analysis of early and late outcomes. Can J Cardiol. 2019; 35:782-90.

4. Rocha RV, Manlhiot C, Feindel CM, Yau TM, Mueller B, David TE, et al. Surgical enlargement of the aortic root does not increase the operative risk of aortic valve replacement. Circulation. 2018;137:1585-94.

5. Tam DY, Rocha RV, Wijeysundera HC, Austin PC, Dvir D, Fremes SE. Surgical valve selection in the era of transcatheter aortic valve replacement in the Society of Thoracic Surgeons database. J Thorac Cardiovasc Surg. 2019;159: 416-27.e418.

6. Tam DY, Wijeysundera HC, Naimark D, Gaudino M, Webb JG, Cohen DJ, et al Impact of transcatheter aortic valve durability on life expectancy in low risk patients with severe aortic stenosis. Circulation. 2020;142:354-64.

7. Tam DY, Dharma C, Rocha RV, Ouzounian M, Wijeysundera HC, Austin PC, et al. Transcatheter ViV versus redo surgical AVR for the management of failed biological prosthesis: early and late outcomes in a propensity-matched cohort. JACC Cardiovasc Interv. 2020;13:765-74.

8. Dvir D, Webb JG, Bleiziffer S, Pasic M, Waksman R, Kodali S, et al. Transcatheter aortic valve implantation in failed bioprosthetic surgical valves. JAMA. 2014;312: $162-70$.

9. Allen KB, Chhatriwalla AK, Cohen DJ, Saxon JT, Aggarwal S, Hart A, et al. Bioprosthetic valve fracture to facilitate transcatheter valve-in-valve implantation. Ann Thorac Surg. 2017;104:1501-8.

https://doi.org/10.1016/j.jtcvs.2020.10.140 